Case Report

\title{
Can Tube Tunnel Crossings Relieve Urban Congestion Problems? Izmir Tube Tunnel Project Proposal Under Scrutiny
}

\author{
Yavuz Duvarc1 ${ }^{1}$ and Tan Yigitcanlar ${ }^{2, *}$ \\ 1 Department of City and Regional Planning, Izmir Institute of Technology, Gulbahce, Urla, \\ Izmir 35230, Turkey; yavuzduvarci@iyte.edu.tr \\ 2 School of Technology, Federal University of Santa Catarina, Trindade, Florianopolis, \\ Santa Catarina 88040-900, Brazil \\ * Correspondence: tan.yigitcanlar@ufsc.br; Tel.: +61-7-3138-2418
}

Received: 3 March 2019; Accepted: 29 April 2019; Published: 1 May 2019

\begin{abstract}
Building underwater tube tunnel crossings to ease the urban congestion problems has become a popular approach for many cities across the globe. London, New York, Istanbul, Hamburg, Sydney and Brisbane are among these cities. However, the effectiveness and externalities of these expensive mega urban infrastructures have also been questioned widely among urban, transport and environmental planning scholars. Given the international popularity of the topic, this study places a new tube tunnel crossings project from Izmir, Turkey under the microscope. In this heuristic simulation study, policy-on scenarios were tested to determine possible impacts of the underwater tube tunnel-crossing project. The traffic impacts are discussed using simulations assigning the initial origin-destination data. The results of the study revealed that, given the two locations, outer and inner locations over the dagger-shape bay, the capacity increments on the bridge links and the links around the periphery highway did not bring any effective solutions beyond some minor improvements. The findings disclosed that the ineffectiveness of the tube tunnel crossing might be due to the excessive congestion happening all over the downtown area, which clogs the passageways to the bridge. The paper highlights the limitations of the tube tunnel-crossing project, emphasises the need for comprehensive investigations before committing to the project and advocates the emphasis to be actually given for sustainable mobility.
\end{abstract}

Keywords: transportation infrastructure; bridge crossing; tube tunnel crossing; traffic congestion; level of service; travel demand modelling; traffic simulation; impact assessment; sustainable mobility; Izmir

\section{Introduction}

Often, major highway and bridge projects are not welcomed by environmentalist groups and some urban planners, as they believe that these projects generally conflict with environmental aims and sustainability outcomes [1-3]. However, traffic congestion is not only about time losses in traffic (and economic imprints), but also environmental externalities; and needs to be addressed urgently, since it is an ever-growing problem interfering with other urban functions [4-6]. While many debates on traffic congestion concentrate on the insufficient number of crossings over the highly congested parts of cities-e.g., bridges over Bosporus in Istanbul (Turkey) - other views advocate that the traffic problem is not a matter of building bridges, but of unbalanced situations between the land use and malfunctioning of transport systems [7-9]. Congestion problems can be tackled effectively through an efficient urban management solution largely favouring sustainable and active transport options over private motor vehicle mobility dependence [10-12]. 
The environmentalist or sustainable view believed that the bridges built by now-such as the ones on Istanbul's Bosporus-have worsened the transport problem, encouraging highway-based and vehicular means of transport in the long-term rather than sustainable means, such as water transport, railed systems or bicycling for both mixed and compact types of cities [13-16]. Such mega-projects may also irreversibly alter the known historical image of cities. Some stated that they and highway-based transportation encouraged the uncontrolled sprawl of development year-after-year, as is the case of Istanbul [16]. In addition, the annual rate of increase in motor vehicles is growing more than the population increase in the city of Istanbul with an increase of around 85,000 every year [7]. Similarly, the average automobilization rate in Izmir (Turkey) is more than 5\% (Figure 1). Apparently, the transport supply cannot catch up with the demand figures, which is one basic source of the traffic congestion on urban streets.

The increased rate of traffic congestions in cities causes drastic socioeconomic and environmental problems (health impacts, more air pollution, noise, stress and so on) as well as time losses that have secondary economic imprints, too, and excessive energy use [17-19]. The noise intensifies in the streets of downtown if especially enclosed by high-rise buildings. Further, when congestion happens, the commuters tend to seek back-street alternatives, which negatively impacts the local community-access roads [18]. Especially, the stop-go slow traffic increases the emission rates to a considerable level [20]. The sustainable solution requires many coherent measures and policies, probably involving bridges and utilising water transportation as well.

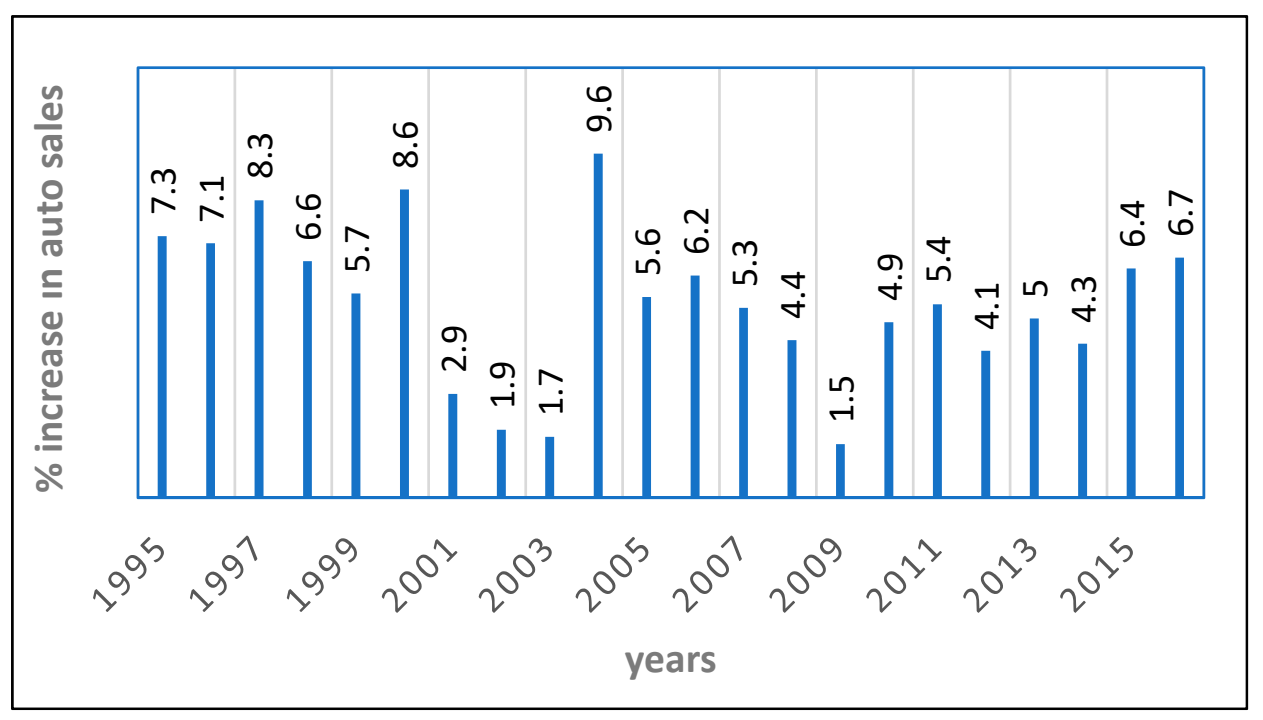

Figure 1. Annual growth rate of car sales in Izmir [21].

Turkey has recently launched many mega transportation projects, including bridges. The new Izmir Tube Tunnel Project (ITTP) proposal, if implemented, will be one of the large-scale transport projects joining the others, including Marmaray and Eurasian Tunnels, Osman Gazi Bridge over the Izmit Gulf and Yavuz Sultan Selim Bridge on Bosporus [7,22]. This study focuses on the local urban traffic impacts of the new underwater crossing projected for Izmir Metropolitan City, known as ITTP, as an example.

Izmir has a U-shape macroform due to its bay that causes quite a difficulty in traffic circulation throughout the city from one end to the other. Thus, the Transportation Ministry of the Central Government proposed an underwater crossing project for Izmir. This project is being debated at the moment; however, the metropolitan and local governments are strongly against it. The opponents (local government agencies) advocate that the crossing's turnover rate would not cover its investment costs, while the proponents (central government agencies) advocate that the project would solve the traffic congestion problems of the city to a greater extent in the long run. Here, it also needs to be noted 
that the big political divide is between the central government (the Justice and Development Party (AKP), an Islamist and conservative political party) and the local governments of Izmir (the Republican People's Party (CHP), a secular and social-democratic political party).

This study is devoted to addressing the following research question: Can a tube tunnel crossing relieve the congestion problem of Izmir? In order to address this question, the study runs an urban travel-demand modelling (TDM) simulation with the TRANUS software package. In an earlier study, the two probable ITTP locations were already determined between the two sides of the bay [23]. The current study uses these locations and assumes it will be toll-free. Through the developed scenarios, the ultimate goal of the study is to understand how the proposed project could help solve or negatively contribute to the existing congestion problems of the city. The simulations are used only to test the utility gained from a shortcut passage in the bay, and only traffic congestion (level of service performance indicator) was investigated. Other socioeconomic or land-use impacts are beyond the scope of this study.

Following this introduction, in Section 2, the impacts of major bridge/tunnel crossings on urban traffic and associated basic simulation approaches for their traffic evaluations are reviewed and presented. Afterwards, in Section 3, the data and simulation methods concerning the case study investigation - the proposed ITTP project in Izmir-are presented. Then, in Section 4, the results of the simulation are presented and discussed-focusing on the congestion levels. Finally, in Section 5, the general conclusions are drawn and some recommendations are put forward.

\section{Literature Background}

\subsection{Impacts of Bridges on Traffic}

Bridges are important infrastructures in overcoming large transport costs-especially for freight-and long travel times [24]. Along with supporting international and interregional goods and people movement, bridges also create advantages for urban transportation. This is the case especially where the city continuity is disrupted geographically, for example, by water bodies [24,25].

Mega bridge projects' impacts go beyond serving solely the local urban needs. For example, five Istanbul bridges on Bosporus connecting Anatolia and Balkans; the Oresund Bridge at Copenhagen connecting Zealand to Funen and thence to the Jutland Peninsula; the Golden Gate in San Francisco between southern and northern California; the Kanmonkyo Bridge between the Honshu and Kyushu Islands in Japan, and so on. Besides transportation, these bridges also have positive economic impacts in their regions [26,27]. For instance, the Hong Kong Zhuhai Macao Bridge (50 km long with $6 \mathrm{~km}$ is sunken tube tunnel) allows the design speed of $100 \mathrm{~km} / \mathrm{h}$ [28], and leads to nearby urban development and also greater economic savings as well as the traffic effects [29].

Supporters of the Izmir Tube Tunnel Project (ITTP) foresee that the project will reduce the amount of external motor traffic to downtown Izmir and, thus, gas emissions will drop significantly [30]. According to this group, economically and socially positive impacts are expected with the increase in estate values around the connecting routes of the bridge. Surely the economic improvement in transportation and the reduced travel times are important for socio-political acceptance of the project and its credibility. However, environmental aspects seem to be heavily neglected by the supporters. This has been the case for many mega-projects that have happened and are happening in Turkey [31].

There is an important question over whether large bridges, functioning for urban transport needs and providing more direct access to other parts of the city, alleviate congestion that would not otherwise happen. This question is frequently asked, especially for the five Bosporus bridges lined up over the Bosporus Strait in Istanbul. In reality, whatever the number of bridges built over the strait, the traffic congestions have not decreased, but have increased proportionately. Traffic is induced by the existence of additional bridges. Some, however, believe that the traffic problems would be much worse if they had not been built. Why are there two such distinct viewpoints even from the transport experts? Which viewpoint is correct? 
Bridges, and especially the big ones, are expensive infrastructure investments, to be constructed for long-time periods. Instead of short-term engineering (capital cost, returns and so on) calculations, there must be long-term (or life-cycle) and multivariate (economic, social, environmental and transport efficiency) cost-benefit calculations [32]; they are built upon the great expectations they bring to the transport economy. Therefore, their net contribution to the economy, the probable impacts and so on, should be well evaluated in the transportation plans from the national/regional to the local/urban level. The basic idea is that their contribution to overall economy and local positive impacts should at least reconcile their insurmountable construction capital costs, which are hard to assess precisely [33]. Yet, these issues are not the concern within the scope of this study.

The environmental and social impacts of such big transportation projects should not be overlooked for the health impacts they may create for the sustainable urban development criteria adopted [13,34-36]. Beyond their local impacts, they are also accused of boosting extra traffic, bringing together the transport-related environmental impacts, which necessitates the economic and environmental impact evaluation in virtual reality before they are implemented. They should also be assessed in terms of their contribution to the environment as providing short cuts and shortened travel lengths. Major transport solutions also need to be integrated with land-use policies and planning [17].

\subsection{Growing Traffic Problems in Urban Areas and Basic Simulation Approaches for Diagnosis}

Today, traffic congestion is one of the most basic ever-increasing urban problems all over the world. Congestion is not only about delays and wasted energy, but also air and water pollution-and thus about contribution to greenhouse gas emissions and environmental pollution [37]. It is usually measured in terms of flow/density relationship and defined as time losses in a queue (if flow exceeds $70-80 \%$ of road capacity, i.e., $\mathrm{v} / \mathrm{c}=1.8)[18,38]$; then, congestion happens either due to the ever-increasing and excessive demands that the existing supply cannot meet, the traffic demands or the infrastructure that cannot be managed well. Most traffic engineers focus on the modelling difficulties of traffic congestion; these are not constant in time but dynamic, which rather requires real-time microsimulation modelling [39-41]. According to Chow et al. [39], not general modelling (first order) but dynamic modelling (second order) in time is the meaningful kind for analysis of change patterns. Macroscopic and static models only provide basic layout for the first-order dynamic models. Analysis of traffic networks has traditionally been based on Wardrop's equilibrium principle, predicting a long-term average state of the network. Today, traffic data-providing firms largely focus on determining real-time congestions, so that the users can know the situation ahead and take their individual decisions while driving to find their routes dynamically [42]. This helps disseminate the congestion.

Consequently, two basic opposing arguments in the explanation of why traffic is increasing day-by-day are: (a) Due to the increased road supply and capacities, leading to the encouragement of excessive travel demand with motor vehicles; (b) due to the inefficiency of existing infrastructure and roads that cannot hold the traffic loads $[20,43]$, causing potential trips to be suppressed. Therefore, the advocates of the first argument propose not building extra roads, infrastructure and bridges. However, having no added infrastructure will not cure, but escalate the problem [10,44-46]. Hence, the advocates of the opposing view think that the added capacity is needed [47-50]. Good management of traffic is the keyword. Basic planning approaches or traffic-based actions include [18,41,43]: (a) Major changes in the road infrastructure or network extension, or improving the existing ones; (b) improvements in public transportation (PT) services, or additional PT lines, and so on; (c) traffic management and traffic signal control, congestion pricing or dynamic route guidance/information and variable message signs (VMS), and other congestion management strategies (reversible roads and the blockade of access or roads, and so on); (d) priority measures as bus signal controls, bus lanes (high occupancy vehicle (HOV) lanes) and guided bus schemes; (e) implementation of ramp metering, or toll roads; (f) use of intelligent transportation systems; $(\mathrm{g})$ land-use control and planning of the city growth, which all may alter congestion levels instantly, or in the long run. 
Usually, transport-demand modelling (TDM) simulations are the basic tools to test the usefulness of policy scenarios, either in a qualitative or quantitative way, be it the results of a single parameter (capacity expansion of roads, demand elasticities to supply) or a bundle of policy measures (decreasing the transit ticket fares, increasing the toll fares and decreasing the availability of carparks together) $[20,50,51]$. In simulations, simple elasticity analyses have been the major method to observe the effect/impact relationships. For example, a study [52] noted that daily vehicle kilometres travelled (VKT) elasticity to supply change as 0.38 through modelling. Additionally, a $1 \%$ increase in capacity causes a $0.8 \%$ increase in traffic growth as an inducement effect. Once ITLUP model was applied to San Francisco; the model simulated the impacts of changing the capacities (usually hypothetical) of the Golden Gate Bridge on the travel times, as well as trip lengths [52]. There, interestingly, the bridge capacity expansion encouraged short distance travels. Similarly, an additional crossing on Thames in London increased the northbound trips by $24 \%$ in the morning peak hours [20]. Systematically changing parameter values, for various cases (such as reducing speeds of private cars while increasing those of transit systems by the same amount), and even for various cities, provided some comparative results about the impacts through model simulations [35,53].

Simulations are useful in learning the various economic (costs, utility, revenues and so on), environmental (energy consumption, air quality) and sustainability impacts (such as trip lengths) and system performances (such as level of service-LOS) of the policies. Yet, they are limited in defining the chaotic extensiveness of the impacts (due to the difficulty in tracking the feedback effects) as far as the parameters introduced into the model system [10]. There is limited empirical evidence whether adding or removing a high-capacity link (or couple of links) seriously affects travel behaviours and alters capacity restrictions on an urban road network [54]. Lately, more complicated and multi-level simulations (i.e., system dynamics) dealing with sub-models of urban issues (economy, society, transport, environment) were used for knowledge-based decision-making [35].

A change in social sub-systems may even have an impact on traffic congestion indirectly through interrelations. Lozano et al. [43] achieved some interesting results out of their simulation study based on a series of scenarios that proposed road extensions and bridges around a university campus in Mexico City, where heavy congestion levels were observed. In the simulations, changing flow directions produced better results than the bridge solutions (including the cost-effectiveness of flow direction). Yet, all proposed solutions (building highway and bridges) induce traffic in even the near-future, which evens out all current-time benefits. The changes in levels of service were detected comparing the policy-off situations to the policy (i.e., after scenarios) situations. Observing first the impacts under different policy scenarios at timeless dimensions is required before the pure impact can be seen in the change analysis (before/after) in different times [20].

Through these previous simulation studies, as through many others, especially for capacity expansions on roads or bridges and so on, two important lessons can be grasped: (a) Improving only a couple of parts of the total system may not be adequate for obtaining effective results but, for a holistic impact, comprehensive and more extensive improvements should be made as much as possible for the whole system (partial improvement of a couple of links on a larger network could cause other links to be affected adversely); (b) the bridges actually attract much traffic towards themselves, and thus may cause traffic congestion at certain spots as the attractor towards the single point, right where the bridge is expected to solve the traffic problem [18]. This is not related to inducement effects, yet.

Nevertheless, the urban geographical shape (macroform) also adds to the complication of traffic distributions as an external factor. Especially for the metropolitan areas that are fragmented into parts by water bodies, rivers, or other geographical threshold features, structures such as bridges are built necessarily to remedy these natural fragmentations. Since these fragmentations are effective in non-uniform distributions of traffic, costly solutions, such as bridges, viaducts and so on, have to be proposed where they are strongly needed, which is a must for the unity of the city. Urban form is seen amongst the land-use parameters as density, activity, texture (granularity) and street layout [55-58]. Therefore, the bridges can be used as proxy parameters replacing the macroform 
by putting in a crossing instead of relieving congestions and longer trips. Yet, amongst the other urban-form parameters, the geographical shape of the city causing deformations in traffic distributions has been an overlooked issue $[59,60]$.

\section{Data and Methods}

\subsection{Methodology}

As mentioned before, the scenario-generation, and thus, the simulation approach is neither a systematic nor a quantitative one, but an overwhelmingly qualitative one-in other words it is a heuristic approach. The only maxim followed through is to remove all congestion in the city as far as possible. To this maxim, the effectiveness of any possible existence of a short-cut crossing between the two sides of the city is to be tested, which is also to test the macroform impact as the basic input in traffic distributions $[57,61,62]$. The heuristic simulation works using hypothetical OD data dating since the 1970s, when the urban space was even fictitious $[24,63,64]$. Then, the varied travel cost figures were obtained for different network structures and urban forms; accordingly, some forms had little congestion and some others considerable $[23,56,63,65]$.

In an earlier study [23], it was observed that, to a greater extent, where the congestions would appear depends on the city macroform and the street network structure. Accordingly, the optimal location of the crossing was defined (that if it were inner side close to the CBD, then the traffic converged to the point of ITTP crossing, with the idea of fast crossing to the other side and giving up the choice of driving up to the peripheral highway, which choked the crossing). The best location had been optimally determined (before the study reported in this paper was conducted) to be between Bostanli and Inciralti districts (Figure 4). Therefore, whether the OD data is actually realistic or not (i.e., is hypothetical) would not matter much.

The macro-simulation tool for simulation processes is determined to be a free version TDM software, i.e., TRANUS, for a simplistic approach. It requires aggregation of data entries into a zone level and accommodates a traditional four-step modelling to estimate traffic volumes on major roadways (primarily freeways, arterials and collectors). It is a suitable program to observe the impacts of various policies through easy-to-do scenario generation [66]. The software utilises basically McFadden's Random Utility Theory, Wilson's Spatial Interaction (for land use/transport integration) Approach and Alonso's Spatial Microeconomics [67]. It is one of the land-use-integrated modelling approaches and uses probabilistic logit models (discrete choice) at every stage of modelling [68]. The software requires solely the OD trip matrix (travel demands) to be entered exogenously. The link attributes speeds by modes, and the capacity information should be introduced. The scenario generation is relatively easily defined by three digits (two integers and one letter) for identification. The scenarios can be produced from the roots of either the base model (base scenario), which is the modelling for current situations, or any other generated scenario.

Up to the trip distributions level (OD matrix), the modelling is done manually. Briefly, after the distributions level, the OD matrix values are input exogenously (not separate matrices for public and private trips). Then, the software does the mode Split and Assignments stage in a combined way alongside the various cost and utility assumptions, and parameter values. These are already used as in their initial (or, originally embedded) values (that is, we do not intervene in the originally defined values, such as the originally defined ticket price, or operation speed of a public transport system). First, the public transport assignments, and, then, the private mode assignments are executed by the synthetic model approach and by the assumptions within the discrete choice model structure, where generalized costs are used to define mode utilities.

All other parameters being the same, the initial OD data are sort of realistic hypothetical, being proportional to the OD matrix originally used (proportionate to the earlier Boesefeldt's transport study data of 1997, simply because of the unreliability issue of the latest transportation study conducted in 2009). The most recent transportation study's final OD results have not been released officially (only 
the brief data) yet. Since the data of the last master plan determined that the average trip rates are almost double the previous ones, all the previous OD matrix values were multiplied by two for the present day. Since precision of the trip values is not the concern in this study and the case area's (Izmir) real traffic problems and the precision of values are not the concern, the Izmir case was taken as a test bed for the simulations, for its special U-shaped form. As shown in Table 1 below, the city currently generates around 5.4 million urban trips per day [69]. As the city has real 1.5 trip rate (in our model it was 1.7), the vehicular trips produced by the model are still very low compared to the real trip values due to the simplicity of the modelling. The study at hand tries to maintain the proportioning (between one third in total and one fourth in both public and private values), instead of values very close to reality (Table 1). Thus, the Izmir city modelled here is sort of, not real Izmir, but a miniature Izmir for analysing the bridge effects.

Table 1. Salient information of Izmir's transportation characteristics—the model results compared to real data [69].

\begin{tabular}{|c|c|c|c|}
\hline Type of Information & $\begin{array}{c}\text { Base Model Total } \\
\text { Travels/Day }\end{array}$ & $\begin{array}{c}\text { Travels for a } \\
\text { Hypothetical Day }\end{array}$ & $\begin{array}{l}\text { Daily Trips and } \\
\text { Their Proportion }\end{array}$ \\
\hline & Base year & Multiplied by 2 & \\
\hline Public & 180,000 & 360,000 & $1,400,000(1 / 4)$ \\
\hline Private & 323,000 & 648,000 & $1,600,000(1 / 4)$ \\
\hline Total & 503,000 & $1,008,000$ & $\begin{array}{l}3,000,000 \text { (walking } \\
\text { excluded) }(1 / 3)\end{array}$ \\
\hline Trip rate (urban) & 0.9/day & $\begin{array}{l}1.7 \text { (mixed with } \\
\text { external trips) }\end{array}$ & 1.5 (almost same) \\
\hline \multirow[t]{2}{*}{ Network attributes } & $\begin{array}{l}\text { (set only for } \\
\text { model system) }\end{array}$ & & \\
\hline & Capacities (hour) & & \\
\hline Highway & $\begin{array}{c}4000 \text { (urban)-12,000 } \\
\text { (peri urban) }\end{array}$ & same & \\
\hline Road type (main streets) & $1000-4000$ & same & \\
\hline All railed systems & 50,000 & same & \\
\hline Private (auto) occupancy & 2 & same & \\
\hline Public mode occupancy & $\% 60$ & same & \\
\hline Frequencies & Metro: $15-30 \mathrm{~min}$ & LRT: $10-15 \mathrm{~min}$ & \\
\hline
\end{tabular}

Izmir's base year OD data were converted into the traffic values through the software and the traffic values were assigned onto the defined network. The network consists of these links: (a) Highways (meaning higher capacities); (b) normal major city streets and boulevards; (c) walkways (which are few in number); and (d) public transport lines as metro and light rail transit (LRT). They all have different capacity levels and link attributes. Yet, capacity assignments can freely be made from one link to another, if necessary. Usually the other parameters were kept untouched in this simulation study. While the basic indicator is LOS (congestion levels) of the links, the control parameters are basically the link/mode speeds, proposing new links (e.g., proposing the water-crossing link), or altering their status (e.g., from road type to highway type), link capacity (incremental increases in acceptable amounts). Level of service is simply the volume over capacity, and has eight categories from A (the least load) to $\mathrm{H}$ (heavily congested) as differentiated in the colours that the TRANUS software yields. The simulation runs are done for two possible ITTP site locations. The parameter and network specifications in detail are not concerned here and are assumed insignificant.

The simulation method processing steps are simply: 
- Running and examining (observing where the congestions occur) the base model results, as the reference for scenario comparisons (base is coded 08a);

- Proposing an initial scenario (project creation) that is to follow the defined maxim (i.e., the removal of the congestions) (the initial simulation is coded as 18a);

- Running and examining the simulation $\left(\mathrm{Sim}_{\mathrm{i}}\right)$ results, and visual comparison to the base scenario whether any improvement occurred (removal of congestions, or any change in LOS levels). The degree of change is observed from the changed colours of links;

- Proposing another scenario that would be more satisfactory, if not, then proceed from level 3 until better results are found.

Usually those policy actions are employed in all simulation trials: (a) Proposing the bridge crossing over the bay (actually there are only two options as 'outer' location away from downtown and 'inner' location closer to the downtown); (b) stepwise (incremental) increase of the link capacities; (c) offering some interim connection roads between the bridge to the nearest highway; and (d) some other minor changes (such as altering link type of a road). Since the major evaluation is visual one, a detailed quantitative assessment method will be deliberately limited here for assessing the simulations' effectiveness. In order to get the targeted results, scenario policy proposals are to be created in a heuristic (or intuitive) way, just by en route learning through the steps of simulation (which is actually the major mission of simulations).

\subsection{Case Study}

Izmir is the port city of western Turkey and is the third largest city (around 3.7 million) in the country. It has lately had a growing economy, and it hosts various economic sectors utilising its commercial and locational advantages, with an average household income of US $\$ 2130$ per month. The basic sectors are trade (import/export), agriculture and agriculture-based industry, electronics and transport. Its port is the third largest one in the country, and has an important share in export/import of products. Automobile ownership is at 160 per thousand people [69].

Nonetheless, the city has struggled from heavy traffic congestions due largely to insufficient road infrastructure and denser settlement structures in recent years. The late urban transport projects have to a degree diverted the travel demands to more sustainable forms and public modes. Yet, the Izmir Bay has an enormous deforming effect on the form of the city (Figure 2); the share of water transportation is still very low [69]. The city basically rolls around the bay. Nevertheless, use of the bay for water transportation for urban travel has probably fallen behind due to the poor intermodality (weakened accessibility of the ferry-ports), although emphasis was put on this in the master transportation plan. The major population foci are the southern and northern sides of the bay, with the most frequented points being the downtown area and the port. In search of the shortest path, the main body of the traffic circulates around the bay, causing densification in the downtown and congestion towards the tip of the bay. It usually takes about 45 to 60 minutes (at peak hours) from the southern point to the northern point of ITTP travelling around the bay (Figure 2), depending on the traffic conditions. 


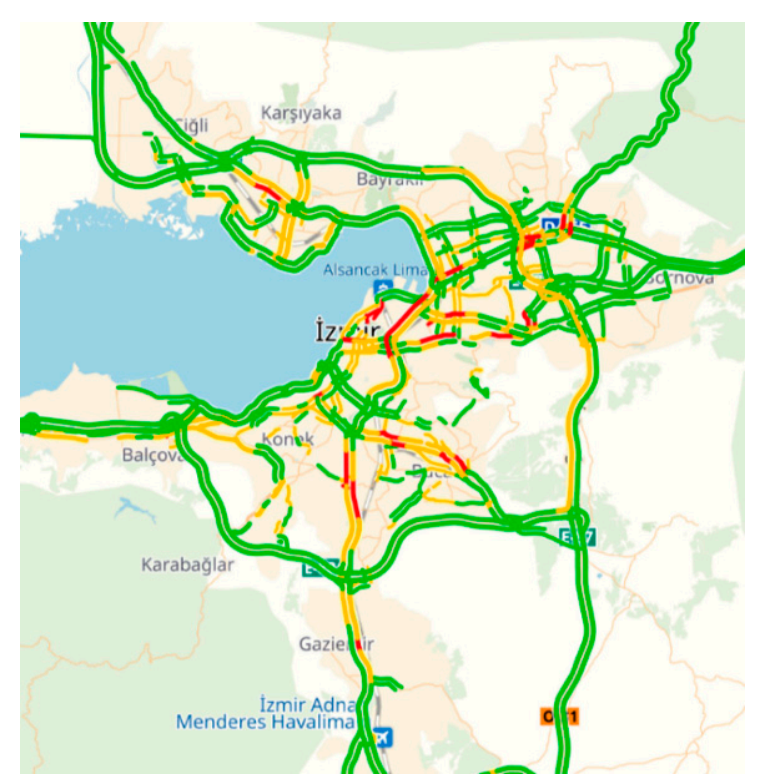

(a)

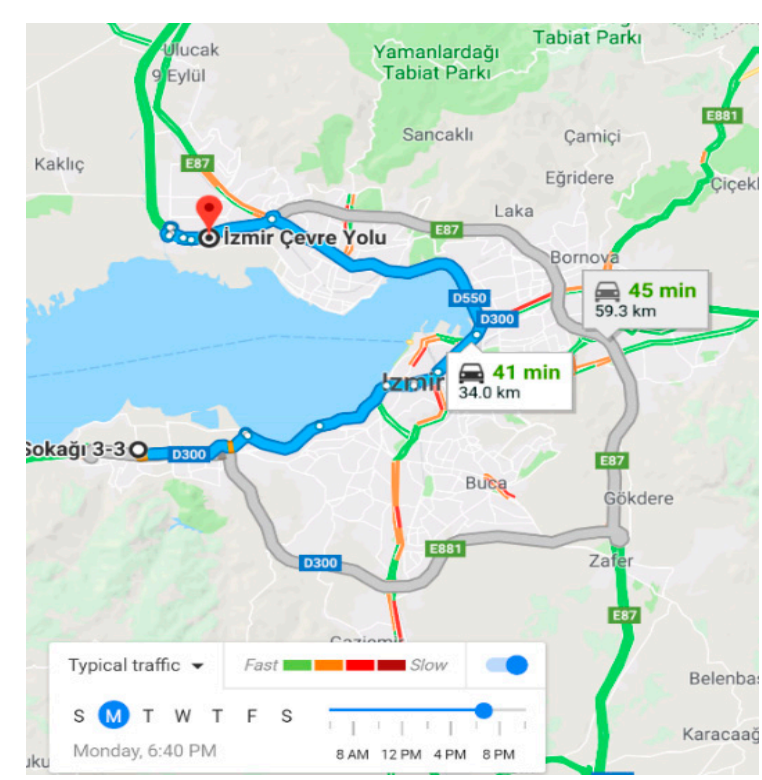

(b)

Figure 2. Actual traffic congestions of a typical weekday evening peak hour in Izmir. (a) Congestion levels; (b) Travel times.

ITTP is one of the most debated project proposals for the city for both its huge building cost, US $\$ 1.6$ billion, and its probable environmental impacts that may affect ecologically sensitive areas (the gulf's natural cleaning systems and other ecological sensitivities like the wetlands where special birds, such as flamingos and dalmatian pelicans, breed at the Gediz River Delta under RAMSAR protection since 1998) [70]. RAMSAR (Convention on Wetlands of International Importance, especially as Waterfowl Habitat), which Turkey joined in 1994, is a convention to protect wetlands and natural habitats. ITTP will tie not only the peripheral highway (the belt motorway), and close the loop, but also the urban railway system. Some parts will be above the water and only a small part (the tube) will be under the water, allowing the passage of ships [71].

\section{Results}

Open access TRANUS software was utilised for running the model and monitoring assignment results. The transport-only module was used, requiring no land-use allocation. Thus, the initial OD (trip distributions matrix) was introduced exogenously (manually). LOS results (i.e., congestion) out of the evaluation process are one of the most important indicators of the program. The software provides static (daily average LOS values if the modelling is done for daily) but not dynamic results. 'Journey to work' and 'journey to school' are considered as the trip purposes in determining travel patterns. The model has a simple network and was run for 15 internal and two external traffic analysis zones. As for public transport mode, there are two operators available in the case of Izmir: (a) Overall bus service (the lines are numerous) that can operate on the city's major streets; (b) railway systems. There is a walk mode, additionally. The bus system is to run on all 'road' and 'highway' type links. Other aspects of the transportation system and the traffic calibration issue with the real data are settled in the simulation model, and are outside the scope of this paper.

\subsection{Congestion Results for the Base Case}

This model simulation shows the existing situation's model assignment results (i.e., LOS results only) without any bay crossing (ITTP) implementation (Figure 3). All other policy-on scenario results are to be contrasted to this base case as the reference. 


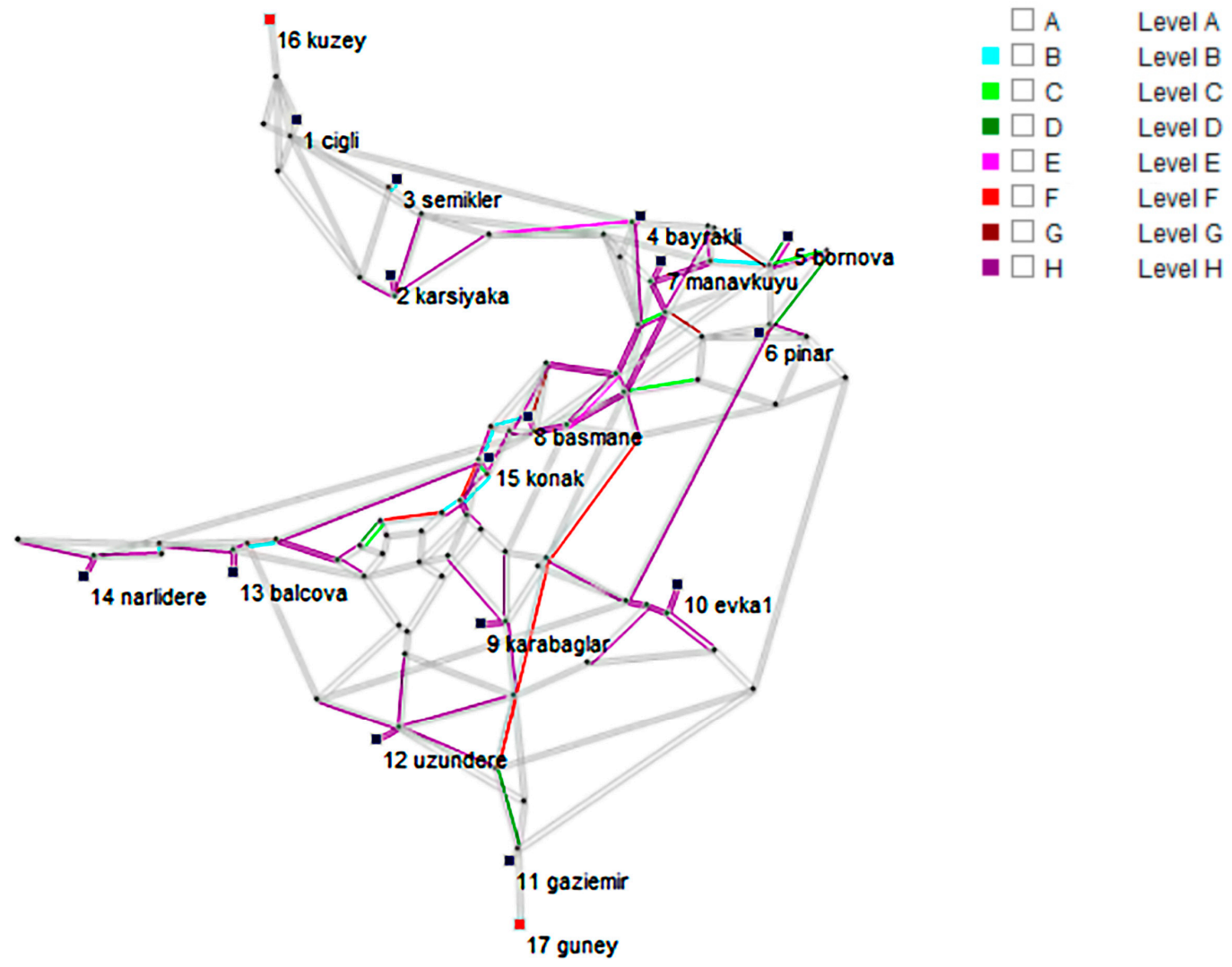

Figure 3. Level of service results of the base scenario (08) with no ITTP.

\subsection{The First Set of Scenarios}

The 18a Scenario: In this first policy-on scenario, the basic inputs were the placement of ITTP on 'outer' location, which lies between the Narlidere district on the southern side and Bostanll district on the northern side of the bay. The capacity was determined to be $4000 \mathrm{pcu}$ per hour. The road type was changed to normal street. From the link type parameter, the average speed for private mode was reduced to $40 \mathrm{~km} / \mathrm{h}$. Beyond F, congestion problems appear (the purple links, which are $\mathrm{G}$ and $\mathrm{H}$ ). In this simulation, it can be observed that congestions decreased little, disappointingly. The ITTP link itself has less traffic (southbound LOS is A, and northbound is B) and the speeds are around $38 \mathrm{~km} / \mathrm{h}$.

The 18b Scenario: In this scenario, the ITTP location is the same (outer) as in the previous scenario. The link capacity of ITTP was increased to 6000 (from the previous 4000) pcu, and the link type was changed to highway. The speed for automobiles was increased to $60 \mathrm{~km} / \mathrm{h}$. When compared to the base case (08a), the policy-off scenario results were: Interestingly, that the outer ITTP location was free from congestion (yet, these good results may be questionable in the sense that ITTP does not attract traffic at all). While it was provided with a daily capacity of 48,000 , it only attracted around 9500 vehicular travels (one side 9100, the other side 9700). ITTP short-cut crossing still has a trivial impact on dissolving overall urban traffic; it removes some congestion on some links, which, yet, still have a positive impact (Figure 4). But, is ITTP investment worth it for this negligible impact?

The 18c Scenario: Almost all parameter inputs are the same as the previous scenario, only ITTP link capacity was increased further to $8000 \mathrm{pcu}$, and an alternative connection (a link) to the periphery highway from Girne Street, to which ITTP connects at the north side, was added (capacity of 6000). As a result of the further capacity increase on the crossing and the highway connection, there appeared a bit of overall relief in the Izmir city. The LOS of ITTP itself is the same as the previous one, LOS A (free-flow traffic).

The 18d Scenario: In this scenario, an additional capacity increase was offered (10,000 pcu) to the structure proposed in the previous simulation (18c). In addition, the capacity was increased from 
6000 to 8000 in the northern connection road to the highway. Still, the change is trivial: While the congestions were removed on some links, there appeared some new congestion on the other links. There is no serious loading on ITTP itself, again all the outer location simulation results can be viewed in Figure 4.
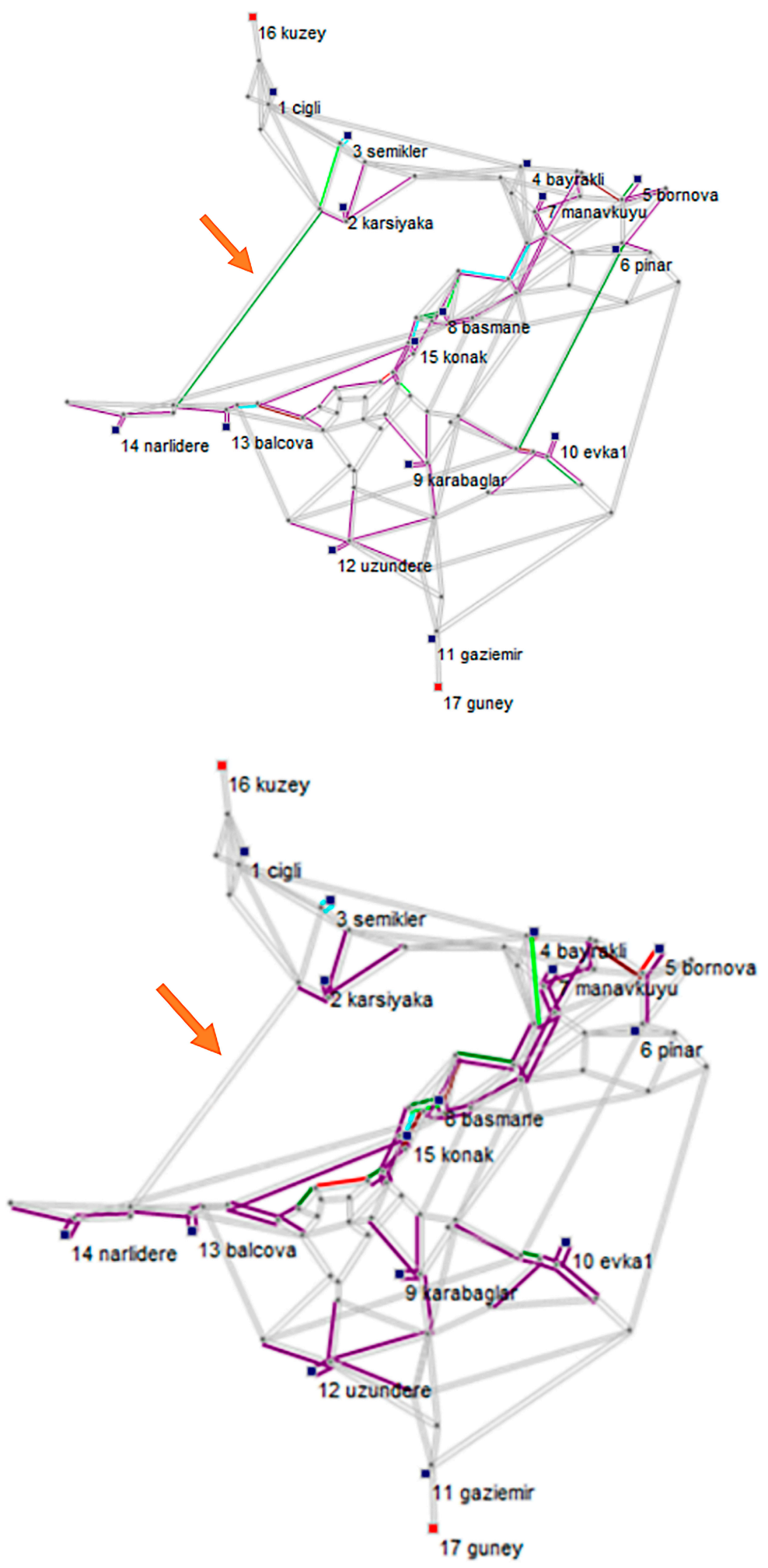

Figure 4. Exemplar scenario results according to outer ITTP location: 18a scenario level of service results (top); 18b scenario level of service results (bottom). 


\subsection{The Second Set of Scenarios}

The 19a Scenario: Together with changing the location of ITTP crossing to nearer to the downtown between the districts Pasaport (south side) and Karsiyaka (north side), more radical changes were expected. ITTP link capacity was again initiated with a lower value of $4000 \mathrm{pcu}$, but the link type was determined to be "highway" this time. The speed for private mode, however, was back to $40 \mathrm{~km} / \mathrm{h}$ again as an 'opening value'. When the congestion levels were checked, we saw that there were as many congested links as the previous scenarios (back as far as the 18a scenario). The ITTP link had one serious LOS $\mathrm{H}$ at one side (northbound).

The 19b Scenario: For this scenario, further capacity (6000) was proposed for the ITTP link. An additional connection link was proposed towards the Çiğli-Şemikler district, with a larger capacity of $6000 \mathrm{pcu}$. As a result of this simulation scenario, there was again further trivial relief in congestion (a couple of congestion areas were removed). One side of the ITTP link was congested.

The 19c Scenario: In this scenario, only capacity increases on both the ITTP link and the northern connection link (both having $8000 \mathrm{pcu}$ ) were proposed. Still further trivial reductions in congestions were observed. The congestion on the ITTP link remained the same as in the previous simulation. Still, the effectiveness of the policy proposals was low and the urban congestion remained the problem.

The 19d Scenario (where highway continuity is provided with ITTP second location choice): The capacities of the ITTP link and the added connection were further increased to 12,000 and 8000, respectively. As a result of this simulation, still only a few removals of congestions were recorded. LOS H remained the same on the same side of the ITTP link. Contrary to the outer one, the inner ITTP location, in this scenario trial, was very much congested (this is not very healthy because it is so congested that the ITTP would not function well). The congestion is probably due to the prior remaining congestion in the streets of downtown; they do not even allow passage down to the ITTP bridge. Rather than the facility that the bridges provide to the clogged traffic, the congestion in the streets towards the bridge needs to be solved primarily. When we visually evaluate the finalised before/after congestion levels, we observe again that ITTP investment will have a trivial impact, not totally removing all congestions, but only a few. Besides, the inner location of ITTP (near downtown) may create a little more congestion around the centre area. The question still lingers: Is ITTP investment worth it for this level of impact? Thus, it can be inferred from these evaluations, as a lesson grasped, if the ITTP project is going to be implemented, the capacity continuity needs to be provided to all links (probably all highway link types) that are integrated with the ITTP link capacity, and the linkages to the inner urban roads must be smooth

The 19e Scenario: The capacity of ITTP was increased to the maximum level of 14,000 pcu. The connection road was increased to 10,000. There are further link additions from the southern tip of the ITTP link towards the south side regions (with capacities of 10,000 pcu). Nonetheless, still very insignificant improvement was obtained.

The 19f Scenario (compared to the base-case LOS results at right side): In this scenario, an exaggerated capacity increase was introduced to the ITTP link: 20,000 pcu. The southern extension (which is connected to the periphery highway at the southern tip) from the ITTP crossing was increased to $14,000 \mathrm{pcu}$. In addition, the existing capacity of the Alaybey Road connection was increased to $4000 \mathrm{pcu}$ (from 1000). Still, no radical removal of congestion in the city but only insignificant improvements on a couple of links were observed. The congestion status remained unchanged. Exemplar inner ITTP location scenarios' results can be observed in Figure 5. 

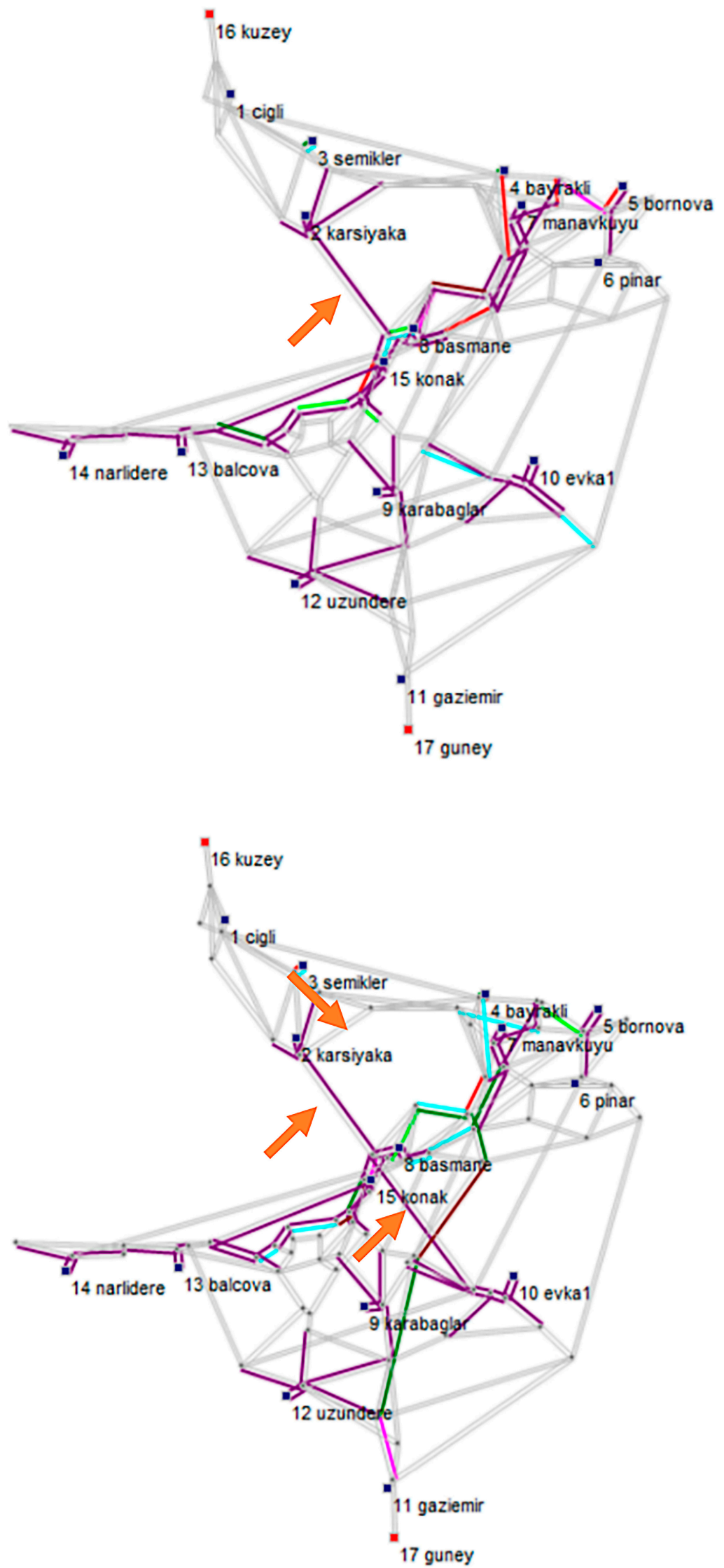

Figure 5. Exemplar scenario results from scenarios 19a (top) and 19f (bottom) according to the inner ITTP location. 
Besides the graphical results for the qualitative evaluation, as in Figure 6, a set of numerical results supports the view of negligible improvement. Even some findings on the total number of congested links bring unexpected results. In general, these results, through the scenarios, support the trivial improvement theory.
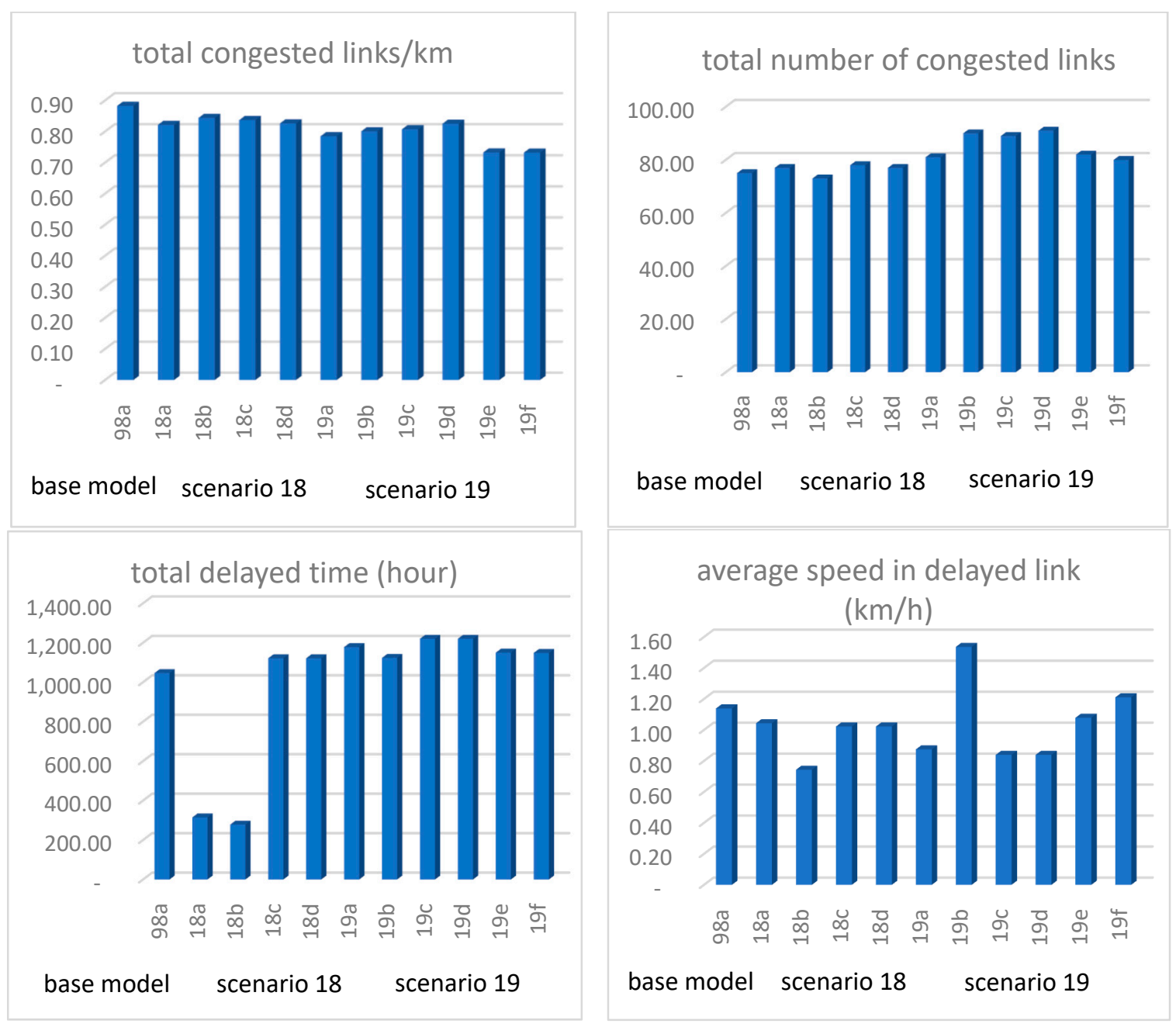

Figure 6. The congested links (only LOS G and H), the speeds and delays per km for all scenarios.

\section{Discussion}

Simulations are useful tools to help policymakers decide on which policies to take, showing which actions work, and which others do not, in a step-by-step (or trial and error) fashion, based on designated scenarios. They are used to reach relatively the most feasible solution(s) after accomplishing a series of trials (simulations). In a complex modelling environment, the basic calculus to arrive at the solution space is just the reckoning of simple input/output relationships that we could either do by elasticity analysis or through comparative evaluation (policy impact analyses) of a bundle of policy measures. Since elasticity analysis, which measures a single parameter's effect on another, is time consuming, the preferred method is usually the total impact assessment, which is a multi-parameter assessment through an intuitive trial of policies. Nevertheless, in this study, the adopted analysis was the assessment of a few parameters with the single parameter of LOS (congestion) over the entire city.

The idea was the removal of all traffic congestion on the city streets. In order to achieve that goal, a hypothesis was put forward such that the anticipated ITTP, a short-cut crossing between the two sides of the Bay of Izmir, a U-shaped city, would be an effective solution. It would relieve traffic pressure in the downtown area, and would be environmentally friendly as well as cost-effective for 
travellers. Because currently most of the travellers (motor vehicles) who want to go from the south side to the north side, or the other way around, must drive unnecessarily, circulating all around the bay (which was verified from the base-model assignment results), and make long trips through congested traffic, the amount of traffic all around the bay is increased, and also greenhouse gas emissions are increased. Thus, whether a short-cut linkage between the two sides, as in ITTP, could be effective in relieving these congestions should be proven by two possible actions: (a) Placing ITTP on the right location over the bay; (b) finding out the appropriate capacity to hold a great amount of traffic, though not all traffic flow causing the congestion is to be channelled through that axis.

On the other hand, when the simulation results were examined, they provided outcomes that were not much expected. Throughout a series of simulation trials with a targeted policy goal, the locating of ITTP and a series of incremental capacity loadings (accompanied also by the connection roads to the nearest high-capacity peripheral highway) did bring some trivial relaxation to the congestion levels, but did not totally eliminate the problem (which was not expected according to the hypothesis). Nonetheless, with limited scenario trials, the following lessons for policy making could be grasped out of this simulation experimentation:

- First of all, just putting a high-capacity crossing in the bay would not solve all the traffic congestion in the city by itself alone if it were surrounded with widespread, persistent and pretty heavily congested streets. In this context, any bridge would be seized by congestion. Furthermore, the heavy traffic diverted to the unique solution bridge would even create more congestion towards the entrance points of the bridge, especially if located around the downtown (inner one).

- Secondly, heavy traffic congestions cannot be solely combatted with bridge solutions. They also required more comprehensive urban and transport planning solutions, including the introduction of smart and sustainable urban mobility and accessibility options.

- Thirdly, all bridge connections should be consistently continuous all throughout the highway network in terms of the link capacities (which the scenario creations did not address within the context of this study, but which a following study may address; there must not be discontinuity, especially in terms of capacities in all connected upper-level roads). Any non-uniformity in all integrated links (especially highway link types) might cause disruption in the flows, and thus, congestion.

- Fourthly, in this study, we only went over the capacity increases of ITTP itself, or the host city's peripheral highway connections (most were added in simulations). However, in this experimental work, only a few heuristic scenario alternatives were created for the highway continuity and uniformity in terms of link types and capacities. Any future similar work should consider this issue more comprehensively.

- Finally, the study also aimed to see the impact of the choice of location for ITTP; that is, whether the outer or inner option would provide better results in dissolving the traffic; the outer meaning away from the city centre (i.e., more integrated with the peripheral expressway) and the inner meaning closer to the centre area. There was no significant advantage of one location over the other, though the outer location option could let the traffic congestion diffuse a little away from the CBD area, where the congestion was a little denser, and the choice for the ITTP route was weakened for the urban travels. With the inner option, however, there was the possibility of a short-cut passage across, especially for the downtown traffic, but with difficulties due to the denser downtown congestion with the inner location of ITTP.

These observations, however, may contain some vagueness and, as explained before, were not so systematically held; they were rather subjectively defined policy trials en route, meaning that some other experts would have much better scenario formulations, link creations, capacity assignments and so on, which would bring results much closer to the targeted objective. Even if simplistic, the model provided almost similar patterns of congestion (almost the same spots) because of the U-shape of the city. 
The record of the unsatisfactory level of congestion removal shows that the adopted policies of, first, just proposing an ITTP over the bay, and then, loading incremental capacities on some links (proposing high capacities on all links at once is not wanted, since it would not be very realistic and feasible) would not be very effective without area-wide consideration. Even proposing a short-cut crossing would draw a lot more traffic to some specific points near it. This would create more traffic (which would not be induced, but attracted to a small area), and congestion, which then would reduce the very meaning of utility that it would bring. Being a bit away from the city, the bridges that have regional and national significance would still be very functional for taking the external traffic away from the urban environment, so that it would not mix with the urban traffic. Maybe, in this sense, they should not be near to cities but a little further away.

Since this study is not about the validity of modelling results, which are different from the representation of local traffic reality, the modelling results can be regarded as hypothetical work in observing the probable impacts of such big bridges that are controversial topics. From this, possible solutions can be derived for capturing probable policy actions. Further, the findings drawn here are not about the regional importance of the bridges.

With this study, the effects of mega-project bridges on city traffic were analysed through simulations of a real case (an anticipated tube tunnel bridge) and of the real city of Izmir, and its real congestions observed almost every day, and some interesting effects were explored unexpectedly. Similar patterns of congestion were simulated in the model environment. Accordingly, even if the effects of mega-project bridges on urban traffic, and the congestion levels per se, were attested through a simplistic simulation approach, the Izmir case taken, and its traffic data, were realistic enough, though perturbed. This was also the case for the anticipated ITTP.

ITTP is currently on the agenda of the city, but it is still not clear whether the project will be applied or not. Thus, the simulation outcomes can be regarded as policy-supporting outcomes concerning whether to support the policy or not, before application, and can be integrated into the general urban transportation policies (not only into Izmir city's). Yet, there are many political, environmental (including aesthetics of the city landscape) and economical debates over its use, harms and the costs and benefits of the project. Leaving aside all other political, social, economic and environmental debates, from the traffic-effects viewpoint, we have the expectation that the bridge will remove a great portion of congestion in the city, causing various impacts, such as saving on travel time, reducing the amount of air pollutants, improving the functioning of city activities, the economy, timely arrivals, so on and so forth. Nevertheless, pertaining to the effects on city transportation, the simulation outcomes provided the following controversial policy learnings:

- Contrary to expectations, the major effect of the bridge, even if optimally located between the two sides, could be over-concentration of traffic (i.e., more congestion) towards where the bridge is located, and around the roads connecting to the bridge. Because, as a solution (or due to the promise of a short-cut passage), the traffic evidently converges towards the bridge location, which creates additional congestion, especially around downtowns.

- Due to the abovementioned convergent traffic problem, the link capacities of the roads connecting to the bridge should be seriously increased. Otherwise, the high capacity of the bridge link alone will not be adequate to solve the congestion problem, and will not provide a short cut to the other side. Then, the bridges will not be solutions but trouble creators. Yet, the connection links should immediately be made into high-capacity (over $8000 \mathrm{pcu} / \mathrm{hr}$ ) highway or expressway (also high-speed) roads (probably the periphery roads) because, if the connections link with the lower-capacity urban roads (even if arterials), the overloaded traffic coming over the bridge may cause sudden bottlenecks in urban streets; then, bridge-connected high-capacity links passing through downtown areas would be required. Thus, conforming to the urban road hierarchy, the bridge traffic needs to be carried over the principal arterials in order to not affect urban traffic. The infusion of traffic from the bridge to the urban streets should be a little indirect and should be affected through a balanced, and well-structured, road hierarchy. 
- Almost all bridge correspondences (connections and other impacted roads) and related road networks should be physically updated, and the capacities (at least the connections to other roads) must be increased. Yet, besides the cost of building the bridge, that kind of upgrading must have high infrastructure costs, which is usually an overlooked, if not ignored, issue. Since the major role of the bridges is to transport external and heavy traffic to the other side with no (or less) damage to the downtown, the bridge connections must be directed to the periphery highways and expressways, primarily at both sides and as quick as possible, so as to get rid of such traffic immediately, but also so as to service the urban traffic in the meantime.

With the points and propositions made above, the utility of bridges in solving congestion and saving on costs can be grasped. Otherwise, in addition to the current expensiveness of such big projects, other congestion-related costs would be added to the existing congestion, which is entirely created by the bridge itself. This would be the very inverse outcome of bridge building. Thus, transport and urban planners and policymakers should consider: (a) Whether the bridge needs to be built or not, considering its abovementioned exploited effects in this study, although a short-cut passage is needed; (b) whether they are ready and they have the ability to take the necessary precautions and make the necessary upgrades (which means extra infrastructure costs) once they have decided to build the anticipated bridge; could the city handle the costs of these capacity additions? Thus, the study especially exploited the utility of such simulation studies, even if simplistic and heuristic, in obtaining such exceptional situations as the chaotic impacts of projects, before they are applied. In policymaking, simulations are truly the only tools to learn and capture the possible effects of policy applications, especially in complex and chaotic network systems and uncertain environments (including political conflicts). These results can be taken into consideration when political debates arise about the utility of costly investments, such as ITTP, as if demonstrating real examples from simulations, once they are brought to the city agenda.

\section{Conclusions}

In search for an answer to the research question-Can a tube tunnel crossing relieve the congestion problem of Izmir? - this study placed Izmir's proposed ITTP project under the microscope. Even with the simple structure of the simulation environment, as used here, we acknowledge the effect of the general shape of the city on the traffic flow patterns, in particular that the form is, to a great extent, shaped by the water bodies. The deformations in the city shape, caused by huge features, such as the bay, may also deteriorate the uniformity of traffic distributions, causing physical inefficiencies and bottlenecks and, therefore, congestion. Bridges, or any type of crossing, are designed for the purpose of eliminating the adverse impacts of such features. Nonetheless, a couple of bridges may not even be sufficient; they can easily be clogged by convergent traffic, and then they themselves become obstacles to traffic flow. Then, their existence poses the very contrary effect of what they promise. If they cannot function properly they can generate congestion, not only on themselves but also on the streets around them. If the other physical (capacity, design speed and so on) and traffic management conditions were not improved in the totality of the city, the bridges' short-cut passage solution would not mean more than a trivial betterment in the total traffic situation.

This study presented this situation through the Izmir case, locating the project proposal of ITTP both on the 'outer' and 'inner' locations over the Izmir Bay. Additionally, through incrementally increasing the capacity of the bridge, in subsequent simulations, accompanied by some connection-road suggestions (with moderate capacities), the overall impact of the bridge construction to the city's traffic congestion was observed. In general, whatever capacity improvement was made, the positive impact on reducing the congestion was, to a great extent, trivial, which brought the consideration over whether building a high-cost project would be worth it-simply because the construction cost of ITTP under the Bay is said to be approximately US $\$ 1.7$ billion, leaving aside its other social and environmental/sustainability costs, which were not considered here. Of course, the time loss and the social, economic and environmental costs of traffic congestion must also be huge and must be taken 
into account; then, we should also make comprehensive and lifecycle cost-benefit calculations again and again. Still, that the trivial (or, not-so-positive) impacts of the bridge projects for the urban local scale are contradictory does not necessarily have to devalue the regional/inter-regional (or national) importance of such mega-projects as Marmaray, the Eurasian Tunnel, the Bosporus bridges, ITTP and so on. Nevertheless, what if they degrade the traffic systems of the urban areas-even if they are functional for regional transport or trade-let alone the precious urban and bay ecosystems?

This case report focused on a specific bridge project from Izmir (i.e., ITTP). Besides the specific case related findings and discussions, the study also generated some other insightful and generalizable findings. These are as follows:

(a) Whatever the contribution of mega-projects like bridges would be to the regional economy, they will not always mean the promise of solving urban congestion effectively (which often depends on the city's overall congestion levels and its macroform) unless they, and their impacts, are conceived area-wide in the totality of the city. This will require not only considering the cost burden of the bridge itself on the society, but also the burden of improving the capacities of all other network structures interlinked with the bridge.

(b) Constructing a bridge may not fully solve traffic congestion if the city traffic in general is already highly congested (since the passageways to the bridge gates will quickly be clogged).

(c) Constructing a bridge may not compensate for the traffic outcomes that result from the form irregularity (the U-shape of Izmir) of the city.

(d) In the case where constructing a bridge does solve congestion (which can be likely for cities that are less hectic, traffic-wise) the benefits must be significant (not trivial, as in the case of Izmir) for the environment, and it must be acknowledged as a sustainable solution, in order to pay off the excessive cost.

(e) In the case where constructing a bridge is not an effective solution due to the ever-loaded traffic in the city, and where the bridge is not built in a way where it is integrated with the city-wide highway network (mentioned in (a), (b) and (c), above), the location effect would not make much difference.

(f) Finally, if the bridge's positive impact is deemed to be trivial (as in this study), then other more sustainable options should be reconsidered alongside it (but, if the impact is significant, their sustainability role should be acknowledged). Even the escalation of congestion towards a single point (to the bridge itself), just because of the bridge's pulling (or attracting) effect, which we might call 'bridges' bottleneck situation (or syndrome)', should be discussed. With this special negative effect, a bridge's would-be positive effects (and the provision of a short-cut passage) are probably evened out.

In light of the above, future studies on verifying the role of bridges in reducing congestion should research various alternative scenarios. However, these prospective studies should also investigate bridges' congestion-increasing effects, and also the new mobility technologies-such as a wider take-up of autonomous vehicles [72,73].

Lastly, the negligence and lack of adequate focus on sustainable transport investment in Izmir, like in many other cities, has led to a decay in the environmental quality of the city-particularly during the last decades $[74,75]$. Along with the increasing sustainability problem, transport disadvantage and social exclusion are also becoming major challenges for the city and are directly impacting the wellbeing of residents [76-79]. We can also add on top of these the lack of adequate travel self-containment solutions in the city [80]. In the presence of such major problems, the priority to be given to a mega-project investment like ITTP raises alarm bells. The unwillingness of the local governments to carry out this project could also pose important resistance to the implementation of the project-where the national government is the key driver behind the project. Furthermore, through empirical exploration, this case report provided invaluable findings and insights into ITTP not being a panacea to the congestion problem of the city. In sum, rather than mega-projects of this kind, limited funds should be directed to improve smart, sustainable and active transport options. 
Author Contributions: Y.D. designed the study, conducted the analysis and prepared the first full draft of the manuscript. T.Y. improved the rigor, relevance and reach of the study, and language edited the manuscript. All authors read and approved the final version of the manuscript.

Funding: This research received no external funding.

Acknowledgments: This research did not receive any specific grant from funding agencies in the public, commercial or not-for-profit sectors. The authors thank Prof. Mark D. Abkowitz, and anonymous referees for their invaluable comments on an earlier version of the manuscript.

Conflicts of Interest: The authors declare no conflict of interest.

\section{References}

1. Yigitcanlar, T.; Kamruzzaman, M. Investigating the interplay between transport, land use and the environment: A review of the literature. Int. J. Environ. Sci. Technol. 2014, 11, 2121-2132. [CrossRef]

2. Perveen, S.; Kamruzzaman, M.; Yigitcanlar, T. What to assess to model the transport impacts of urban growth? A Delphi approach to examine the space-time suitability of transport indicators. Int. J. Sustain. Transp. 2018. [CrossRef]

3. Perveen, S.; Yigitcanlar, T.; Kamruzzaman, M.; Hayes, J. Evaluating transport externalities of urban growth: A critical review of scenario-based planning methods. Int. J. Environ. Sci. Technol. 2017, 14, 663-678. [CrossRef]

4. Dur, F.; Yigitcanlar, T. Assessing land-use and transport integration via a spatial composite indexing model. Int. J. Environ. Sci. Technol. 2015, 12, 803-816. [CrossRef]

5. Kamruzzaman, M.; Yigitcanlar, T.; Washington, S.; Currie, G.; Turrell, G. Australian baby boomers switched to more environment friendly modes of transport during the global financial crisis. Int. J. Environ. Sci. Technol. 2014, 11, 2133-2144. [CrossRef]

6. Yigitcanlar, T.; Dur, F. Developing a sustainability assessment model: The sustainable infrastructure, land-use, environment and transport model. Sustainability 2010, 2, 321-340. [CrossRef]

7. Gercek, H.; Demir, O. Urban Mobility in Istanbul; Final Report; French Development Agency: Paris, France, 2008.

8. Akyüz, E. The solutions to traffic congestion in Istanbul. J. Acad. Soc. Sci. 2015, 3, 442-449.

9. Kamruzzaman, M.; Hine, J.; Yigitcanlar, T. Investigating the link between carbon dioxide emissions and transport-related social exclusion in rural Northern Ireland. Int. J. Environ. Sci. Technol. 2015, 12, 3463-3478. [CrossRef]

10. Goonetilleke, A.; Yigitcanlar, T.; Ayoko, G.; Egodawatta, P. Sustainable Urban Water Environment: Climate, Pollution and Adaptation; Edward Elgar: Cheltenham, UK, 2014.

11. Arbolino, R.; Carlucci, F.; Cirà, A.; De Simone, L.; Ioppolo, G.; Yigitcanlar, T. Factors affecting transport privatization: An empirical analysis of the EU. Transp. Res. Part A Policy Pract. 2018, 110, 149-160. [CrossRef]

12. Yang, J.; Yuan, M.; Yigitcanlar, T.; Newman, P.; Schultmann, F. Managing knowledge to promote sustainability in Australian transport infrastructure projects. Sustainability 2015, 7, 8132-8150. [CrossRef]

13. Cervero, R.; Kockelman, K. Travel demand and the three Ds: Density, diversity and design. Transp. Res. Part D Transp. Environ. 1997, 2, 191-219. [CrossRef]

14. Ewing, R.; Handy, S. Measuring the unmeasurable: Urban design qualities related to walkability. J. Urban Des. 2009, 14, 65-84. [CrossRef]

15. Newman, P.; Kenworthy, J. The ten myths of automobile dependence. World Transp. Policy Pract. 2000, 6, 15-25.

16. Güney, E. A study on the effect of transportation systems to the evolution of the city image-The case of Istanbul. Megaron 2012, 7, 91-107.

17. Black, D.; Black, J. A review of the urban development and transport impacts on public health with particular reference to Australia: Trans-disciplinary research teams and some research gaps. Int. J. Environ. Res. Public Health 2009, 6, 1557-1596. [CrossRef]

18. Robinson, R. Problems in the Urban Environment: Traffic Congestion and Its Effects; University of Wollongong Research Online, Wollongong Studies in Geography: Wollongong, Australia, 1984.

19. Awosusi, A.; Akindutire, I. Urban traffic congestion and its attendant health effects on road users in Ado-Ekiti, Nigeria. Int. Multidiscip. J. Ethiop. 2010, 4, 434-446. [CrossRef]

20. Hansen, M.; Gillen, D.; Dobbins, A.; Huang, Y.; Puvathingal, M. The Air Quality Impacts of Urban Highway Capacity Expansion: Traffic Generation and Land Use Change; UC Transportation Center: Berkeley, CA, USA, 1993. 
21. Turkish Statistical Institute. Road Motor Vehicle Statistics 2019. Available online: http://www.turkstat.gov.tr/ Start.do (accessed on 28 February 2019).

22. Gocer, K. Türkiye'nin stratejik önemini etkileyen 21. Yüzyıl büyük bölgesel projelerin fırsat ve tehditlerine yönelik analizi (The analysis of the opportunities and the threads of the 21st century regional mega-projects affecting the strategic importance of Turkey). In Proceedings of the Planlamada Yeni Politikalar ve Stratejiler: Riskler ve Firsatlar (New Policies and Strategies in Planning: The Risks and Opportunities), Istanbul, Turkey, 7-9 November 2005; pp. 13-18.

23. Duvarci, Y. The uncertainties in defining the Izmir's transportation policies and a scenario-based approach proposal. In Proceedings of the 2nd International Izmir's Transportation Symposium, Izmir, Turkey, 8-9 December 2009; pp. 121-127.

24. Rodrigue, J. The Geography of Transport Systems; Routledge: New York, NY, USA, 2013.

25. Papacostas, C.; Prevedouros, P. Transportation Engineering and Planning; Prentice Hall: Englewood Cliffs, NJ, USA, 2001.

26. Cerato, R. The Oresund Bridge and the Commuting Trends; Master Programme in Economic Growth, Innovation and Spatial Dynamics, School of Economics and Management, Lund University: Lund, The Netherlands, 2010.

27. Hill, R.W. The Chesapeake Bay Bridge-Tunnel: The Eighth Wonder of the World; John Day Co.: New York, NY, USA, 1972.

28. Hussain, N.; Wong, C.; Carter, M.; Kwan, S.; Mak, T. Hong Kong Zhuhai Macao Link. Procedia Eng. 2011, 14, 1485-1492. [CrossRef]

29. Clements, R. A Social and Environmental Impact Assessment That Examines the Impacts That Have Resulted from the Construction and Operation of the Channel Tunnel. Master's Thesis, University of Canterbury, Christchurch, New Zealand, 2006.

30. Belkaya, H.; Lykke, S. Marmaray project: The project and its management, tunnelling and underground space technology. In Engineering Earth: The Impacts of Megaengineering Projects; Brunn, S., Ed.; Springer: Berlin, Germany, 2005.

31. Yigitcanlar, T.; Bulu, M. Dubaization of Istanbul: Insights from the knowledge-based urban development journey of an emerging local economy. Environ. Plan. A 2015, 47, 89-107. [CrossRef]

32. Duvarci, Y.; Selvi, Ö.; Gunaydin, H.; Gur, G. Impacts of Transportation Projects on Urban Trends in Izmir; IZTECH: Urla, Turkey, 2008; pp. 1175-1201.

33. Wang, C.; Zhao, F.; Guo, S.; Guo, H. Research and evaluation on the effect of urban road reconstruction from the perspective of ecological environment. Adv. Transp. Stud. Int. J. 2015, 1, 187-192.

34. Newman, P.; Kenworthy, J. Sustainability and Cities: Overcoming Automobile Dependence; Island Press: Washington, DC, USA, 1999.

35. Chen, C.; Shao, L.; Xu, L.; Shang, J. A case study predicting environmental impacts of urban transport planning in China. Environ. Monit. Assess. 2009, 157, 169-177. [PubMed]

36. Banister, D.; Berechman, J. Transport Investment and Economic Development; UCL Press: London, UK, 2000.

37. Mahbub, P.; Goonetilleke, A.; Ayoko, G.; Egodawatta, P.; Yigitcanlar, T. Analysis of build-up of heavy metals and volatile organics on urban roads in Gold Coast, Australia. Water Sci. Technol. 2011, 63, 2077-2085. [CrossRef] [PubMed]

38. Akcelik, R. Travel time functions for transport planning purposes: Davidson's function, its time-dependent form and an alternative travel time function. Aust. Road Res. 1991, 21, 49-59.

39. Chow, A.; Li, Y.; Gkiotsalitis, K. Specifications of fundamental diagrams for dynamic traffic modelling. Asce J. Transp. Eng. 2015, 141, 04015015. [CrossRef]

40. Kotsialos, A.; Papageorgiou, M. The importance of traffic flow modeling for motorway traffic control. Netw. Spat. Econ. 2001, 1, 179-203. [CrossRef]

41. Liu, R.; Vliet, D.; Watling, D. Microsimulation models incorporating both demand and supply dynamics. Transp. Res. Part A 2006, 40, 125-150. [CrossRef]

42. Duvarci, Y.; Sargin, F.; Inan, E. Testing accuracy of immediate traffic data and its evaluation for transportation planning. In Proceedings of the International Advanced Researches \& Engineering Congress (IAREC-2017), Osmaniye, Turkey, 16-18 November 2017; pp. 2666-2676.

43. Lozano, A.; Granados, F.; Guzman, A. Impacts of modifications on urban road infrastructure and traffic management: A case study. Procedia Soc. Behav. Sci. 2014, 162, 368-377. [CrossRef] 
44. Cervero, R. Road expansion, urban growth, and induced travel: A path analysis. J. Am. Plan. Assoc. 2003, 69, 145-163. [CrossRef]

45. Litman, T. Generated traffic and induced travel, implications for transport planning. ITE J. 2001, 71, 38-47.

46. Litman, T. Induced Travel Impact Evaluation; Victoria Transport Policy Institute: Victoria, BC, Canada, 2005.

47. Litman, T. Changing travel demand: Implications for transport planning. ITE J. 2006, 76, 27-33.

48. Mokhtarian, P.; Salomon, I. How derived is the demand for travel? Some conceptual and measurement considerations. Transp. Res. Part A 2001, 35, 695-719. [CrossRef]

49. Duvarci, Y.; Mizokami, S. A suppressed demand analysis method of the transportation disadvantaged in policy making. J. Transp. Plan. Technol. 2009, 32, 167-194. [CrossRef]

50. Nijkamp, P.; Blaas, E. Impact Assessment and Evaluation in Transportation Planning; Kluwer Academic Publishers: Amsterdam, The Netherlands, 1994.

51. Zhao, P. Car use, commuting and urban form in a rapidly growing city: Evidence from Beijing. Transport. Plan. Technol. 2011, 34, 509-527. [CrossRef]

52. Putman, S. Integrated Policy Analysis of Metropolitan Transportation and Location; Department of Transportation, Assistant Secretary for Policy and International Affairs, Superintendent of Documents; GPO, 1980. Available online: https://catalog.lib.unc.edu/catalog/UNCb3712057 (accessed on 28 March 2019).

53. Wegener, M.; Mackett, R.; Simmonds, D. One city, three models: Comparison of land-use/transport policy simulation models for Dortmund. Transp. Rev. 1991, 11,1-12. [CrossRef]

54. Billings, J.; Garrick, N.; Lownes, N. Changes in travel patterns due to freeway teardown for three North American case studies. Urban Des. Int. 2013, 18, 165-181. [CrossRef]

55. Handy, S. Methodologies for exploring the link between urban form and travel behaviour. Transport. Res. Part D 1996, 1, 151-165. [CrossRef]

56. Zorlu, F. Kentsel Doku-Ulaşım Sistemi Ilişkileri (Urban Texture-Transportation Interrelationship); METU JFA: Ankara, Turkey, 2008; pp. 81-104.

57. Duvarci, Y.; Kilic, A.; Erol, Ö. Ulaşım planlamasında unutulmuş parametre: Kent makroformu (The forgotten parameter in transportation planning: Urban macroform). In 1. Ulusal Planlamada Sayisal Modeller Sempozyumu; Istanbul Technical University: Izmir, Turkey, 2010; pp. 563-575.

58. Maat, K.; Timmermans, H. A causal model relating urban form with daily travel distance trough activity/travel decisions. Transp. Plan. Technol. 2009, 32, 115-134. [CrossRef]

59. Shatu, F.; Yigitcanlar, T.; Bunker, J. Shortest path distance vs. least directional change: Empirical testing of space syntax and geographic theories concerning pedestrian route choice behaviour. J. Transp. Geogr. 2019, 74, 37-52. [CrossRef]

60. Shatu, F.; Yigitcanlar, T. Development and validity of a virtual street walkability audit tool for pedestrian route choice analysis-SWATCH. J. Transp. Geogr. 2018, 70, 148-160. [CrossRef]

61. Kenworthy, J.; Laube, F. Automobile dependence in cities: An international comparison of urban transport and land use patterns with implications for sustainability. Environ. Impact Assess. Rev. 1996, 16, 279-308. [CrossRef]

62. Cervero, R. Built environments and mode choice. Transp. Res. D 2002, 7, 265-284. [CrossRef]

63. Senbil, M.; Fujiwara, A. Development of a choice model for evaluating sustainable urban form. Proc. East. Asia Soc. Transp. Stud. 2005, 5, 2164-2178.

64. Hay, A. Transport for the Space Economy; MacMillan: London, UK, 1973.

65. Hunt, J.; Miller, E.; Krieger, D. Current operational urban land-use transport modelling frameworks: A review. Transp. Rev. 2005, 25, 329-376. [CrossRef]

66. De la Barra, T. Integrated Land-Use and Transport Modeling: Decision Chains and Hierarchies; Cambridge University Press: Cambridge, NY, USA, 1989.

67. General Description of the Tranus System (TRANUS Manual). Available online: http://www.tranus.com (accessed on 17 September 2018).

68. McFadden, D. The Measurement of Urban Travel Demand. J. Public Econ. 1974, 3, 303-328. [CrossRef]

69. Bogazici Proje. Transport Planning of Izmir (UPi Report 2030); Izmir Büyükşehir Belediyesi (Izmir Greater City Municipality): Izmir, Turkey, 2017.

70. Meric, B.; Cagirankaya, S. Turkey's Important Wetlands: RAMSAR Sites (Report); Ministry of Forestry and Water Affairs: Ankara, Turkey, 2013. 
71. Izmir Tube Tunnel Project (ITTP Project). Available online: http://www.tmmmb.org.tr/images/Etkinlikler/9 TMK/ozgur_ugurlu.pdf (accessed on 2 June 2018).

72. Yigitcanlar, T.; Wilson, M.; Kamruzzaman, M. Disruptive impacts of automated driving systems on the built environment and land use: An urban planner's perspective. J. Open Innov. Technol. Mark. Complex. 2019, 5, 24. [CrossRef]

73. Faisal, A.; Yigitcanlar, T.; Kamruzzaman, M.; Currie, G. Understanding autonomous vehicles: A systematic literature review on capability, impact, planning and policy. J. Transp. Land Use 2019, 12, 45-72. [CrossRef]

74. Yigitcanlar, T. Rethinking Sustainable Development: Urban Management, Engineering, and Design; IGI Global: Hershey, PA, USA, 2010.

75. Yigitcanlar, T. Sustainable Urban and Regional Infrastructure Development: Technologies, Applications and Management: Technologies, Applications and Management; IGI Global: Hershey, PA, USA, 2010.

76. Yigitcanlar, T.; Mohamed, A.; Kamruzzaman, M.; Piracha, A. Understanding transport-related social exclusion: A multidimensional approach. Urban Policy Res. 2019, 37, 97-110. [CrossRef]

77. Duvarci, Y.; Yigitcanlar, T.; Alver, Y.; Mizokami, S. Variant concept of transportation-disadvantaged: Evidence from Aydin, Turkey, and Yamaga, Japan. J. Urban Plan. Dev. 2010, 137, 82-90. [CrossRef]

78. Kamruzzaman, M.; Yigitcanlar, T.; Yang, J.; Mohamed, M. Measures of transport-related social exclusion: A critical review of the literature. Sustainability 2016, 8, 696. [CrossRef]

79. Duvarci, Y.; Yigitcanlar, T.; Mizokami, S. Transportation disadvantage impedance indexing: A methodological approach to reduce policy shortcomings. J. Transp. Geogr. 2015, 48, 61-75. [CrossRef]

80. Yigitcanlar, T.; Dodson, J.; Gleeson, B.; Sipe, N. Travel self-containment in master planned estates: Analysis of recent Australian trends. Urban Policy Res. 2007, 25, 129-149. [CrossRef]

(C) 2019 by the authors. Licensee MDPI, Basel, Switzerland. This article is an open access article distributed under the terms and conditions of the Creative Commons Attribution (CC BY) license (http://creativecommons.org/licenses/by/4.0/). 